RESUMO O artigo enfoca a construção da Inspetoria Geral das Estradas de Ferro, organizada pelo grupo dirigente do Clube de Engenharia, vitorioso nos embates do $1^{\circ}$ Congresso de Estradas de Ferro do Brasil (1882). Naquela década, as ações políticas já não passavam unicamente pelos tradicionais partidos políticos. $\mathrm{O}$ processo de formação do bloco no poder no Brasil, que se elaborava por disputas entre as diferentes frações - lutando cada qual pela prevalência de seus interesses particulares - comportava cada vez mais porta-vozes e agências em conflito. Uma agência que centralizasse todo o sistema viário teria forte impacto sobre a correlação de forças políticas vigentes, mesmo em uma era de incertezas.

Palavras-chave Estado, Clube de Engenharia, estradas de ferro.

ABSTRACT This article focuses on the construction of the General Inspectorate of Railroads, organized by the Club of Engineering leading group, winner of debates during the $1^{\text {st }}$ Brazilian Railroads Congress (1882). On that decade, a political action no longer went exclusively through the traditional political parties. The development process of the power block in Brazil that was developed by disputes among the different sides - each one fighting for the predominance of its interests - entailed more spokesmen and agencies. An agency that could centralize the entire road system would have a strong impact on the correlation of the political forces, even at a time of uncertainty.

Keywords State, Engineering Club, railroads.

\section{Porta-vozes em uma era de}

incertezas: o Clube de Engenharia

e a concepção de uma inspetoria

geral das estradas de ferro

Spokesmen in an age of uncertainty: the Engineering Club and the design of a railroad general inspectorate

\section{PEDRO EDUARDO MESOUITA DE MONTEIRO MARINHO}

Museu de Astronomia e Ciências Afins | MCT

Em um certo ponto de sua vida histórica, os grupos sociais se separam de seus partidos tradicionais, isto é, os partidos tradicionais naquela dada forma organizativa, com aqueles determinados homens que os constituem, representame dirigem, não são mais reconhecidos como sua expressão por sua classe ou fração de classe. [...] Fala-se de "crise de autoridade": e isso é precisamente a crise de hegemonia, ou crise do Estado em seu conjunto. [...] A classe dirigente tradicional, que tem um numeroso pessoal treinado, muda homens e programas e retoma o controle que lhe fugia com uma rapidez maior do que a que se verifica entre as classes subalternas; faz talvez sacrifícios, expõe-se a um futuro obscuro com promessas demagógicas, mas mantém o poder, reforça-o momentaneamente.

\section{Antonio Gramsci}

\section{Introdução}

A partir das últimas décadas do século XIX, intelectuais tecnocientíficos formados pela Escola Politécnica foram capacitados para atividades profissionais relacionadas com as grandes obras públicas e demais intervenções em benefício da comercialização de produtos primários para a exportação. Em linhas gerais, engenheiros, primeiramente agremiados no Instituto Politécnico Brasileiro (IPB) e, mais 
tarde, no Clube de Engenharia (CE), passaram a atuar como técnicos e como dirigentes nas Companhias de Estradas de Ferro, cuja função particular articulava-se, naquele momento, aos interesses das frações do complexo agroexportador de determinadas regiões do país.

Ao fim daquele século, na formação social brasileira a conflituosa correlação de forças que sustentava o bloco no poder passou a demonstrar a perda da capacidade de formulações intelectuais capazes de articular reformas compatíveis com o momento histórico. Avizinhava-se a privação da mão de obra escrava e as frações da classe dominante alimentavam o temor quanto à desestruturação do modelo econômico que, há décadas, as favorecia. A crise de hegemonia conjugava-se à crise política. Não sem razão o ano de 1880 começa com a chamada Revolta do Vintém, passa pela criação da Sociedade Brasileira contra a Escravidão e termina com a fundação do Clube de Engenharia, sintomas da crise e, simultaneamente, do processo de ampliação do Estado brasileiro. Cabe ressaltar que todas essas distintas frações lutavam entre si e articulavam-se, buscando alianças que as colocassem em posição de assumir a condução de um novo projeto hegemônico. Entretanto, o momento era de incertezas.

Neste estudo, interessa-nos a constituição de um relevante grupo de quadros com formação tecnocientífica, diplomados na Escola Central/Politécnica e agremiados nas duas instituições acima referidas. 0 centro da análise encontra-se particularmente em sua organização no âmbito da sociedade civil e a construção de sua representatividade efetivada na formulação de uma agência geral das estradas de ferro no Brasil, no período final da monarquia. Nesse processo, a complexidade e diversidade de interesses e conflitos que compunham as diversas frações de classe integradas ao bloco no poder caracterizariam, como contexto primordial de organização, a sociedade civil que se tornava também mais complexa.

Naquele momento histórico, nos estertores do escravismo e do regime monárquico, a economia, a política e, consequentemente, as relações sociais apresentavam-se mais elaboradas e intricadas. A população no Brasil, que, em 1822, era aproximadamente de três milhões, já ultrapassava quatorze milhões na década de 1880. Despontava um esboço de mercado interno e surgiam novos empreendimentos como possibilidade de aplicação do capital cafeeiro que se diversificava, favorecendo o surgimento de uma expressiva infraestrutura. Em meio a esse complexo contexto, engenheiros civis e empresários a eles ligados passaram a vislumbrar a definição de sua aliança, cuja formação é resultado do processo de associação entre empresa e indústria favorecidas pela cafeicultura. Exemplo dessa aliança é a sua presença nos serviços urbanos de abastecimento de água, energias, saneamento, estradas de ferro, transporte urbano, dentre outros.

Dessa maneira, neste artigo procuraremos refletir sobre a organicidade destes engenheiros "diplomados" nas condutas empresariais das companhias de estradas de ferro em particular, dentro das quais os agentes em questão reuniam capitais, atuavam no planejamento e realização dos projetos técnicos, assim como nas concepções ideológicas das construções. Portanto, acreditamos ser possível explicar como os projetos ligados às ferrovias que eram concebidos dentro do Clube desdobravam-se de forma a extrapolar a sociedade civil em direção à sociedade política, revelando, assim, uma significativa disputa hegemônica que é parte de um processo de ampliação do Estado brasileiro.

\section{Os engenheiros civis e a sua "escola prática”, as ferrovias}

Com o processo de montagem do chamado complexo cafeeiro, na segunda metade do século XIX, a construção civil, sem dúvida uma das mais antigas atividades profissionais desenvolvidas no Brasil, ampliou imensamente suas perspectivas de atuação e, ao mesmo tempo, enfrentou desafios, tanto de ordem econômica quanto técnica. As grandes obras necessárias à criação da infraestrutura urbana, energética e de transportes construída nessa época ofereceram desafios de toda ordem que se confundem com as origens da engenharia brasileira. 
Na década final do Império brasileiro, com efeito, a Engenharia Civil encontrava-se, num primeiro momento, estreitamente vinculada à expansão e diversificação das condições de produção agrário-exportadora; vinculada, portanto, igualmente aos agentes nela implicados. 'Tal processo dava-se concomitantemente no âmbito urbano - com os serviços de locomoção, calçamento, saneamento, gás, abastecimento de água - e, no âmbito rural, com a construção das estradas de ferro e das linhas telegráficas que as acompanhavam. Tal conjuntura guardava relação direta com a expansão capitalista e as concepções ideológicas burguesas de progresso, técnica e competência, que demandavam a formação de agentes tecnocientíficos condicionados às funções mais complexas e, dessa maneira, dotados de capacidade para a execução e direção de atividades vinculadas ao desenvolvimento econômico.

No processo de expressivo aumento da demanda das frações hegemônicas pelo trabalho do engenheiro civil, as frentes de trabalho se multiplicavam, mas o que aparecia em destaque era a demanda relativa a toda a sorte de obras públicas nas cidades e de atividades diretamente ligadas à construção e administração de estradas de ferro - ainda que, inicialmente, a participação do engenheiro brasileiro tenha ocorrido na qualidade de auxiliar dos engenheiros ingleses. Ao longo desse processo, os profissionais ligados à Engenharia brasileira conseguiram galgar gradativamente postos de direção em agências no aparelho estatal, trajetória que pode ser observada principalmente em relação às ferrovias nacionais. Na E. F. D. Pedro II, por exemplo, principal ferrovia do país, todos os principais postos de direção eram ocupados por engenheiros brasileiros no início da década de $1870 .^{2}$

Ao mesmo tempo que se demandava o trabalho dos engenheiros civis para as obras de infraestrutura, o crescimento das cidades ampliava ainda mais sua atuação em diferentes campos e, consequentemente, aumentava a necessidade de novos e maiores espaços para as suas discussões. Poder-se-iam encontrar, de maneira frequente naquele período, publicações de artigos e realização de debates dos engenheiros cujas temáticas estavam relacionadas aos chamados "melhoramentos"3 urbanos. Nas revistas científicas em especial, os agentes costumavam registrar a questão das obras públicas, particularmente estradas de ferro, como um dos assuntos mais recorrentes, demonstrando o envolvimento intenso de sua prática profissional ao processo de crescimento e transformação do espaço urbano no fim do século e, assim, os vínculos estabelecidos com as frações agrárias hegemônicas, conforme já apontamos.

É possível perceber, por exemplo, que nas sessões do IPB, de 1862 a 1880, assim como nas memórias publicadas na Revista, preponderaram temas relativos ao planejamento, construção e administração geral de ferrovias. Dos estudos premiados com a medalha Hawkshaw, 35,7\% diziam respeito a estradas de ferro. ${ }^{4}$

Da mesma forma, como podemos verificar na tabela abaixo, o tema de maior destaque na Revista do Clube de Engenharia, cuja primeira publicação data de 1887, prossegue referente às estradas de ferro, seguido de obras públicas:

\section{Temáticas da Revista do Clube de Engenharia (1887-1910)}

\begin{tabular}{ll}
\hline Temas & Total \\
\hline Estradas de Ferro & 95 \\
\hline Abastecimento de água & 23 \\
\hline Saneamento & 18 \\
\hline Portos & 12 \\
\hline Máquinas a vapor & 7 \\
\hline Navegação & 6 \\
\hline Eletricidade & 4 \\
\hline Telegrafia & 4 \\
\hline Telefonia & 2 \\
\hline Aço & 2 \\
\hline Cimento portland & 1 \\
\hline Vários & 22 \\
\hline
\end{tabular}

FONTE: Revista do Clube de Engenharia. Rio de Janeiro: Imprensa a Vapor Lombaerts \& C. / Tip. Leuzienger \& Filhos (1887-1910). 
Além da publicação de temáticas ligadas às obras públicas em revistas das próprias agremiações, a organização de congressos conseguia reunir um número expressivo de agentes com o propósito de discutir diretrizes para a política de incremento das indústrias e ferrovias no país. Nesse sentido, as problemáticas formuladas e debatidas por aqueles intelectuais em suas reuniões cotidianas eram tornadas temários de seus congressos, aptos a promover campanhas as mais diversas, resultando na consolidação daqueles agentes no que consideramos como intelectuais organizadores da cultura. Algumas resoluções formuladas nesses encontros foram registradas em relatórios e pareceres, cujo conteúdo é passível de revelar não apenas a preeminência de um grupo particular, mas também certas contendas estabelecidas entre os agentes sobre os assuntos em questão. Na década de 1880, dois encontros ganharam destaque: $01^{\circ}$ Congresso das Estradas de Ferro do Brasil, em 1882, e a $1^{\text {a }}$ Exposição das Estradas de Ferro do Brasil, realizada em 1887, que foram organizados pelos dirigentes do Clube de Engenharia e cujo material empírico correspondente ao congresso de 1882 servirá adiante para nossa análise.

Envolvidos intensamente na viabilização do "complexo econômico" que surgia, os engenheiros se organizavam, negociavam, disputavam e estabeleciam alianças no âmbito da sociedade civil, ao mesmo tempo que inscreviam agentes na sociedade política, com vista a realizar ações particulares e salvaguardar os seus próprios interesses e da classe que representavam, quaisquer que fossem as frações hegemônicas dentro dos complexos agroexportadores que conseguiam fazer girar, sob a sua órbita, a vida econômica do país.

Consta de extensa literatura especializada que investiga o fim do Império, ${ }^{5}$ a transformação das estradas de ferro na principal indústria brasileira do período, cuja característica fundamental era a manutenção da monocultura de exportação do café. Todavia, ao mesmo tempo que seu traçado foi planejado a fim de garantir a produção e exportação do café, as ferrovias, em vários momentos distintos, também se destinaram a outros propósitos, tais como 0 transporte de passageiros, de gêneros agrícolas e mercadorias diversas (algodão, açúcar, milho, sal etc.), de produtos importados (como o combustível para os próprios empreendimentos ferroviários), além de artigos para as famílias dos fazendeiros. Os mineiros de fora da Zona da Mata, por exemplo, conforme afirma Blesenheim, precisavam vender seus produtos de granja, fazendas e minas, ${ }^{6}$ assim como a mão de obra escrava fluminense, de acordo com Andrea Rabello, devia ser alimentada, sendo que parte dos produtos necessários, como farinha, feijão e toucinho, chegava através das estradas de ferro. ${ }^{7}$ Concomitante ao fato de que as linhas concentravam tais funções, elas conseguiam aproximar habitantes de diferentes regiões e províncias, possibilitando a ligação e o estabelecimento de alianças entre grupos sociais e regionais distintos. Portanto, é preciso nos determos no fato de que o advento ferroviário, iniciado na década de 1850, tinha em seu bojo aspectos que envolviam uma gama de interesses conexos e também diversos. Dentre os grupos e agentes implicados nessa indústria, encontravam-se os capitalistas estrangeiros (norte-americanos, franceses e, especialmente, ingleses), investidores e sócios das linhas (incluindo alguns fazendeiros), os proprietários nacionais das estradas de ferro, os grupos regionais proprietários das lavouras de café que disputavam espaços dentro do próprio complexo agroexportador, os proprietários das demais lavouras de menor importância para o comércio de exportação, além dos profissionais da engenharia que, em muitos casos, tornaram-se diretores das vias, concessionários dos ramais e implicados com a própria comercialização do café.

Até o momento, consideramos possível afirmar que, uma vez diagnosticada a relação entre engenheiros e as Companhias de Estradas de Ferro, e dessa indústria com a fração hegemônica do complexo agroexportador cafeeiro, os agentes investigados - intelectuais organizados na sociedade civil - estavam, num primeiro momento, estreitamente vinculados a tais frações hegemônicas. Contudo, este "técnico modernizador" vivia um contexto histórico marcado por profundas e rápidas modificações em níveis socioeconômico, político e cultural. Seu projeto modernizador e industrialista, aprendido nas escolas de engenharia e partilhado com os agentes vinculados ao capital internacional, confrontava-se com um sistema escravista governado por um Imperador. Ora, as agitações e contendas que incidiam sobre a sociedade como um todo, alicerçadas pela desagregação do Império, atingiam em cheio os agentes em análise. No entanto, isso não significa que todos os engenheiros em questão levantassem bandeiras abolicionistas ou industrialistas. A complexidade que marca a transformação do regime - característica da década de 1880 - é também substância da complexidade da própria análise das questões que eles defendiam. Tal aspecto apresenta-se como chave interpretativa 
importante para a compreensão, na análise realizada adiante, de quais interesses estavam implicados nos debates, além daqueles diretamente relacionados com a manutenção de sua posição e status profissional. Ressaltamos que, embora tenham sido os anos de 1880 a 1890 o auge das construções ferroviárias, os engenheiros não estavam restritos somente à "engenharia ferroviária". Na realidade, como sublinhado em outros trabalhos, ${ }^{8}$ o processo se iniciara rumo a uma ampliação dos espaços profissionais, empresariais e políticos, tanto na sociedade civil, quanto na sociedade política. Exemplo dessa conjectura é o início de um conjunto de legislações que apontava para o eixo urbano como campo de trabalho especializado e demais serviços que se instalariam ao longo da república, tais como os decretos que iniciam as concessões de serviços de telefonia. A respeito deles, destacamos que Charles Paul Mackie, estadunidense integrante do Grupo Dirigente do Clube de Engenharia e empresário com fortes ligações políticas, foi concessionário dos serviços de telefonia, benefício garantido após a sua aproximação da agremiação.

\section{O Clube de Engenharia, um "partido” em construção}

A concepção de Estado ampliado formulada por Gramsci toma como questão básica a premissa de que esse mesmo Estado se amplia e torna-se mais complexo mediante a incorporação progressiva de "aparelhos privados de hegemonia". A partir da matriz gramsciana de "Estado ampliado", visto como uma relação social entre sociedade civil e sociedade política, estamos considerando não somente seus aparelhos de coerção - que visam e possibilitam uma dominação - mas, também, como capaz de produzir e reproduzir uma direção moral, intelectual e, portanto, cultural, exercida por uma fração de classe ou grupo social sobre outras frações ou grupos.

Antonio Gramsci dedicou uma grande parte da sua obra escrita nos cárceres fascistas à concepção de hegemonia. Sua noção ia muito além do poder exclusivo de dominação, baseando-se, sobretudo, na perspectiva de que

... a hegemonia pressupõe que se deve levar em conta os interesses e as tendências dos grupos sobre os quais a hegemonia será exercida; que se forme certo equilíbrio de compromisso, isto é, que o grupo dirigente faça sacrifícios de ordem econômico-corporativa. Mas também é indubitável que os sacrifícios e o compromisso não se relacionam com o essencial, pois se a hegemonia é ético-politica também é econômica; não pode deixar de se fundamentar na função decisiva que o grupo dirigente exerce no núcleo decisivo da atividade econômica. ${ }^{9}$

0 conceito de hegemonia elaborado por Gramsci tinha um alcance maior do que a noção vulgar de um domínio exclusivo, uma vez que sua concepção inclúía e ultrapassava, ao mesmo tempo, dois conceitos anteriores: o de cultura como todo um processo social, a partir do qual os homens elaboram e delineiam suas vidas, e o de ideologia, no restrito sentido de um sistema de significados e valores como mera projeção de interesses de classe. Portanto, nessa acepção, a maioria dos subalternos compartilha valores e normas que justificam e garantem a dominação do grupo dominante e, por consequência, restringem a construção de uma alternativa a essa mesma dominação, ainda que o sistema pareça injusto. Por outro lado, Gramsci aponta para a possibilidade de, a partir da vontade criativa, uma classe ou grupo social interferir na história a partir de uma nova elaboração hegemônica. Nesse processo, o grupo social em questão deve se constituir potencialmente em hegemônico, num processo de elaboração crítica formulada por seus intelectuais, com vista a esse mesmo grupo superar seu momento econômico-corporativo específico. Essas relações de classe, perpassadas por diversas mediações, se traduzem na ligação orgânica estabelecida com os seus intelectuais, a fim de constituir um bloco intelectual, convertendo-se de classe dirigida em classe dirigente e, talvez, dominante.

Observando tal complexidade, podemos perceber a importância da ação institucional organizada dos vários grupos sociais articulados a esse processo. No Rio de Janeiro, instalaram-se e atuaram, da segunda metade do século XIX em diante, diversas organizações da sociedade civil. Várias delas foram decisivas na elaboração de importantes formulações, ao mesmo tempo que as principais propostas apresentadas revelavam os interesses específicos dos grupos sociais e frações de classe que cada uma representava. 
É nesse momento que surge o Clube de Engenharia, fundado em 24 de dezembro de 1880 num sobrado de uma casa comercial da Rua do Ouvidor. Em março do mesmo ano já havia sido fundada a Associação dos Engenheiros no Comércio do Rio de Janeiro, o que demonstra a intenção de se institucionalizarem as relações dos engenheiros com outros grupos sociais.

Uma das maneiras possíveis de pensar o Clube de Engenharia, constituído ao longo das últimas décadas do século XIX, juntamente com o processo de ampliação do Estado brasileiro, é tomá-lo como partido ideológico constituído como "intelectual coletivo". Em outras palavras, é possível perceber que a agremiação adotava questões específicas das frações de classe que procurava representar e, ao unificar interesses e difundir visões de mundo, atuava como um aparelho hegemônico, ${ }^{10}$ possibilitando a inserção dessas frações em diferentes esferas de poder. 0 Clube de Engenharia foi responsável pela organização, representação e institucionalização - tanto no âmbito da sociedade civil quanto no âmbito da sociedade política - dos interesses de determinados grupos sociais. Ao unificar interesses e difundir visões de mundo, atuou como "partido" no sentido gramsciano.

Assim, o que buscamos é ressaltar a importância que os dirigentes imperiais reservaram aos intelectuais dos quadros técnicos e científicos. Nesse sentido, basta considerar a importância reservada às reformas e regulamentos do ensino superior. Desde cedo, ainda sob domínio português, o contingente de engenheiros militares em circulação na colônia era significativo, tanto quanto a presença das primeiras "Aulas de Fortificação" e "Academias" no esforço contínuo para a formação de quadros específicos. ${ }^{11}$ Não se formava apenas um grupo para atividades formalmente burocráticas, mas também professores, engenheiros, médicos, advogados, artistas, enfim, intelectuais com forte organicidade à classe dominante e, por isso mesmo, chamados a elaborar planejamentos e ações governamentais e a garantir capacidade de formação escolar para futuras gerações.

Os grupos dirigentes perceberam, ao longo do exercício da direção política, a atenção que deveria ser dispensada ao bom planejamento de suas ações intervencionistas, traduzindo-as em políticas públicas. Assim, ao longo do quarto final do século XIX, as frações dominantes, mantidas coesas por seus intelectuais, mobilizaram-se para aprovar um conjunto de leis que buscavam, energicamente, coibir e/ou disciplinar as esferas da existência social que permaneciam à margem ou refratárias das políticas públicas. 0 que se observou foi que as novas funções reguladoras da sociedade civil urbana dinamizaram o conflito intraclasse dominante. No caso específico das vias de comunicação, os "embates" ocorriam principalmente no contexto da regulamentação dos transportes, na esfera da nova legislação referente às desapropriações e na "disciplina" das construções.

Destacam-se, assim, importantes questões advindas da ação institucional dos diversos grupos sociais que se consolidaram com a passagem do século XIX ao XX, que possibilitam pesquisas e análises dos novos grupos profissionais e proprietários que construíam seu locus no "bloco no poder" naquele momento. Com a organização de seus interesses mediante os aparelhos privados de hegemonia, e a pressão por sua inscrição frente a determinados organismos do poder, tenderam a constituir um peso significativo na correlação de forças vigente. ${ }^{12}$

\section{Congressos tecnocientíficos: os engenheiros civis como protagonistas}

A maioria dos agentes do Clube de Engenharia esteve à frente de Companhias de Estadas de Ferro, fossem elas de propriedade privada nacional ou estrangeira, ou administradas por intermédio de agências na sociedade política. Em geral, eles ocupavam os cargos de engenheiro civil, engenheiro-chefe, engenheiro fiscal, chefe de serviço telegráfico, diretor, diretor técnico, presidente, engenheiro condutor, chefe de linhas, chefe de tração e consultor, para citar alguns exemplos. Alguns poucos aparecem, na documentação analisada sobre o Clube de Engenharia, como fundadores e proprietários. Há também um número mais significativo de agentes cujos registros nos documentos indicam terem sido membros de comissões para o estudo da viabilidade das linhas e de ramais. ${ }^{13}$ 
As duas companhias onde se pode encontrar um maior número de dirigentes da agremiação ocupando postos de trabalho e direção são, em primeiro lugar, a Estrada de Ferro Dom Pedro II, conforme citado anteriormente, e, em segundo, a Estrada de Ferro Leopoldina. Obviamente, a maioria deles estabeleceu vínculos com outras ferrovias e ramais na mesma época ou em épocas distintas às suas funções nessas duas empresas.

De acordo com Gramsci, a hegemonia de um "centro diretivo" sobre o conjunto dos intelectuais se afirma mediante duas linhas principais: 1) "uma concepção geral da vida, uma filosofia a qual ofereça aos seguidores uma 'dignidade' intelectual que dê um princípio de diferenciação e um elemento de luta contra as velhas ideologias coercitivamente dominantes"; e 2) "um programa escolar, um princípio educativo e pedagógico original, que alcance e dê uma atividade própria, em seu campo técnico, àquela fração dos intelectuais que é mais homogênea e a mais numerosa". Gramsci segue argumentando a respeito dos "congressos de cientistas", que teriam "uma dupla eficácia": 1) "reunir os intelectuais do nível mais elevado, concentrando-os e multiplicando sua influência"; e 2) "obter uma concentração mais rápida e uma orientação mais decidida nos intelectuais de níveis inferiores, que são levados normalmente a seguir os universitários e os grandes cientistas por espírito de casta". ${ }^{14}$

Com base nessa matriz teórica e na oportuna referência feita pelo autor marxista italiano, passamos a analisar a primeira organização congressual, em âmbito nacional, organizada pelo que viemos denominando em outros estudos de "Grupo Dirigente do Clube de Engenharia". 15

Uma vez analisados os registros do congresso ${ }^{16}$, parece-nos pertinente afirmar que a fundação do Clube de Engenharia, ocorrida em 1880, consolida-se, de fato, com a instalação e repercussão do $1^{\circ}$ Congresso de Estradas de Ferro do Brasil (CEFB), em 1882, uma primeira reunião em âmbito nacional a debater assuntos ligados às ferrovias e demais questões da Engenharia Civil. Naquele momento, a agremiação se fortalece como aparelho privado de hegemonia, com potencial de inscrição de demandas na sociedade política, assim como com a capacidade de construção de consensos na sociedade civil e reafirmação de políticas públicas nessa esfera.

Dessa forma, consideramos fundamental discorrer sobre essa concretização no "interior" da própria associação, sobre o conjunto de ações que envolveram a capacidade de construção de consensos por parte dos quadros agremiados no Clube de Engenharia. Exemplo dessa atuação foi, notadamente, a reunião do $1^{\circ} \mathrm{CEFB}$. A simples menção à capacidade de mobilização efetivada pela agremiação em torno de quase todos os representantes das estradas de ferro nacionais, a participação dos principais dirigentes imperiais, inclusive o Imperador, nas sessões desse Congresso e, sobretudo, a capacidade de inscrição na sociedade política de algumas das demandas vitoriosas nas diversas seções, apenas um ano após a sua realização, permite-nos afirmar nossa hipótese com maior profundidade e empiricamente.

Como parte de uma estratégia política de contínua inscrição de propostas mediante a realização de congressos e exposições, o grupo dirigente do Clube logrou constituir-se como porta-voz de um significativo aparelho privado de hegemonia, formulador de consensos e, por isso mesmo, organizador da cultura. Assim, ao $1^{\circ} \mathrm{CEFB}^{17}$ se seguiu, cinco anos depois, a $1^{\text {a }}$ Exposição das Estradas de Ferro do Brasil (1 ${ }^{\mathrm{a}}$ EEFB), também patrocinada pelo Clube em 1887. Essa prática se repetiria no período republicano com saldos positivos em termos de representatividade na efetivação de políticas públicas.

\section{Primeiro Congresso das Estradas de Ferro do Brasil (1882)}

Na sessão de 29 de outubro de 1881, convocada pelo Conselho Diretor do Clube de Engenharia, foi discutida e deliberada a proposta do seu presidente, Antonio Augusto Fernandes Pinheiro, para instituir na cidade do Rio de Janeiro, sob patrocínio do Clube, um Congresso anual, devendo tratar de "todas as questões que interessam às Estradas de Ferro". De acordo com a proposta, $01^{\circ}$ CEFB deveria ser formado por delegados e administradores das Companhias de Estradas de Ferro, representantes das respectivas repartições fiscais, sócios do Clube de Engenharia e, ainda, pelos 
engenheiros que optassem por participação individual. Também fora aprovado que as informações prestadas pelas diversas companhias, assim como as atas do Congresso, deveriam ser publicadas por responsabilidade do Clube, além das despesas com a instalação e demais encargos do mesmo Congresso:

O Conselho Diretor do Clube de Engenharia, fundado na cidade do Rio de Janeiro, tem a honra de remeter a V. E. o incluso prospecto da instituição de um Congresso das Estradas de Ferro do Brasil, e espero que V. E. tomando em toda consideração essa idéia de cuja realização tantas vantagens devem resultar para as nossas estradas de ferro e para o desenvolvimento da viação pública, não só ministrará as informações de que trata o mesmo prospecto, mas também fará representar a si naquele Congresso por um delegado a - que V. - tão dignamente dirige. Nas informações trocadas, nas discussões que se tratarem nas exposições que cada um fizer, vê o Clube de Engenharia um grande passo para o melhoramento de cada empresa. A experiência e os conselhos de uns, os melhoramentos por ele realizados, serão proveitos o ensinamento para outros; e a união de tantos interesses e de tantas forças, já por si respeitáveis necessariamente dará um resultado do maior alcance para a prosperidade do país. Confiado atenção que a idéia do Congresso das estradas de ferro do Brasil encontrará no espírito ilustrado de V. - o Conselho Diretor do Clube de Engenharia espera que $V$. - lhe comunicará até 1 de maio próximo, a nomeação de seu delegado e em tempo conveniente a remessa das informações relativas a essa estrada de ferro. ${ }^{18}$

Já no primeiro dia de janeiro de 1882, seria emitida uma circular dirigida a todas as administrações e repartições de Estradas de Ferro. Assinavam a circular os sócios que constituíam o Grupo Dirigente do Clube de Engenharia. ${ }^{19} 01^{0}$ CEFB deu-se, assim, sob o comando desse grupo dirigente, inclusive com toda a composição da sua diretoria reproduzida na direção empossada para os trabalhos do Congresso. Ocupando também a presidência do congresso, Antonio Augusto Fernandes Pinheiro ${ }^{20}$ ficou responsável pela condução dos trabalhos.

0 cronograma previsto para o Congresso manteve-se ativo e, após findar o prazo para a remessa das informações dos delegados das respectivas Estradas de Ferro, era lido, na sessão de 15 de junho de 1882 do Clube, um ofício do ministro da Fazenda comunicando ter colocado à disposição do Clube um salão do edifício da Tipografia Nacional para que ocorressem as sessões do Primeiro Congresso das Estradas de Ferro do Brasil. ${ }^{21}$

A sessão solene de inauguração e a primeira sessão ordinária do Congresso realizaram-se em um dos salões do pavimento superior do prédio da Tipografia Nacional às 20 horas de 7 de julho de 1882, quando compareceram o Imperador e o conde d'Eu, sob a presidência de Fernandes Pinheiro. Também estiveram presentes na solenidade, além de todo o Grupo Dirigente do Clube de Engenharia, representantes da imprensa e de diversas corporações e outros convidados, e ainda aqueles tantos que representavam os principais agentes envolvidos nas atividades ligadas à Engenharia Civil. Ao todo, foram realizadas treze sessões: nos dias 7, 11, 17 e 26 de julho; 1, 8, 14 e 29 de agosto; e 5, 12 e 19 de setembro.

No momento do Congresso, o Clube de Engenharia não havia completado dois anos, mas já agregava quadros destacados e com experiência em outras associações da sociedade civil, como o Instituto Politécnico Brasileiro. Pinheiro, ele mesmo ex-membro desse Instituto, iniciou a primeira sessão fazendo uso da palavra na condição de atual presidente daquela agremiação. Segundo ele, a intenção do Clube de Engenharia centrava-se principalmente em:

... Reunir, portanto, esses elementos esparsos, essas forças até hoje isoladas, é multiplicar-lhes os efeitos, e estes - bem o sabeis - não crescem unicamente na razão simples daquelas forças. [...] Muitas dessas questões, que temos esboçado, estariam hoje resolvidas se houvesse junto ao Ministério das Obras Públicas um - Conselho Superior Consultivo. [...] Dessa viciosa organização de um serviço todo especial e onde devia de haver pelo menos uma seção essencialmente técnica; um Conselho Superior Consultivo [...]. Pra muitas não bastará a reunião deste Primeiro Congresso, mas teremos assim lançado as bases para a sua solução, despertando o estudo que essas questões reclamam. Muitas dependem da intervenção do Governo e maior número ainda da intervenção da opinião pública... ${ }^{22}$

Portanto, a perspectiva de inscrição de uma agência na sociedade política já era explicitada nas propostas introdutórias do $1^{\circ}$ CEFB pelo presidente do Clube de Engenharia, logo aclamado como presidente do referido Congresso. 
Em seu discurso de abertura, Pinheiro revelava a disposição de apresentar um encaminhamento das propostas que seriam discutidas, mas já destacava a convicção de que somente com a criação de um Conselho Superior Consultivo seriam efetivadas as resoluções e pareceres do Congresso.

Antonio Fernandes Pinheiro, além de ter sido o primeiro Presidente do Clube de Engenharia, foi um dos principais idealizadores da reunião nacional para reflexão sobre as estradas de ferro, dirigindo diversas reuniões daquela agremiação com a finalidade de elaboração de temários que conduziriam as discussões do Congresso das Estradas de Ferro, como, por exemplo, aprofundamento dos decretos que regulavam a concessão de estradas de ferro, uma vez que envolvida "com muitas disposições úteis e que abonam a ilustração do ministro que as referendou, encontra-se uma injustificável, indébita e perniciosa intervenção de governo em questões que são e devem ser de exclusiva e absoluta competência das associações". ${ }^{23}$

Cabe ressaltar que, ao longo da ação profissional dos engenheiros civis, as Superintendências e Diretorias de Obras Públicas constituíram agências de forte disputa entre frações de classe, visando ao aparelhamento desta ou daquela demanda política no âmbito do Estado restrito, ou mesmo à inserção de agentes naquela esfera. Tais conflitos tinham a sua razão de ser em se tratando das vias de comunicação, uma vez que estas estavam diretamente relacionadas com as agências que formulariam as políticas públicas relativas às estradas de ferro e demais grandes obras públicas a serem efetivadas em todo o Império. Assim, a urgência para com a situação da produção agrícola atravessava grande parte do Congresso, tendo-se sempre o cuidado, por parte de seus dirigentes, para que possíveis soluções voltadas
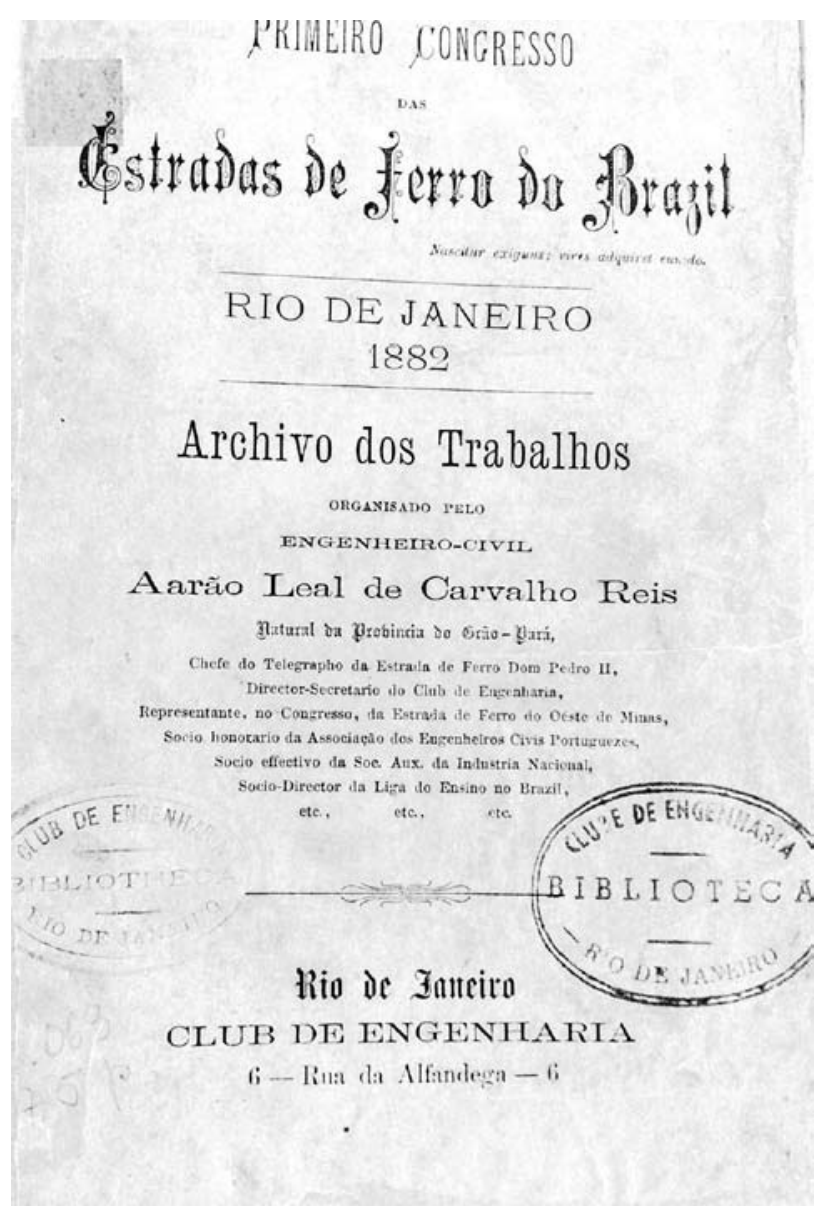

Capa dos anais do Primeiro Congresso das Estradas de Ferro do Brasil.

Fonte: REIS, Aarão Leal de Carvalho (org.). Primeiro Congresso das Estradas de Ferro do Brasil. Archivos dos Trabalhos. Rio de Janeiro: Club de Engenharia, 1882. (Biblioteca do Clube de Engenharia). para a produção agrária exportadora não colidissem com a relevância das companhias de estradas de ferro, uma vez que agentes envolvidos nessas empresas também compunham o quadro dirigente daquela agremiação.

É possível afirmar que, ao ampliarem seu campo de ação, conforme dito anteriormente, os engenheiros adquiriram um prestígio maior junto aos órgãos administrativos, bem como junto às frações hegemônicas de então, atestando a sua capacidade de mobilização e representatividade. Nesse contexto, pelo papel que representavam no âmbito intelectual brasileiro, os profissionais ligados às atividades de engenharia civil constituíam um significativo grupo de representantes e participantes das decisões políticas. Exemplo disso foi a capacidade do Grupo Dirigente do Clube, organizado em reuniões ordinárias, de preparar o evento. 0 material remetido aos convidados para o Congresso continha os regulamentos e a ordem dos temários do encontro e, dentro deles, as próprias questões a serem debatidas.

Tal movimento manifestava o papel dirigente do Clube de Engenharia junto a seus quadros de base, nos quais, dessa maneira, disciplinava-se o que seria discutido e de que modo, adotando-se encaminhamentos que configurassem um conjunto de questões as quais, em síntese, apontavam para a defesa de dois pontos principais: 1) o fortalecimento e a reafirmação de políticas públicas ligadas às estradas de ferro em atendimento às demandas dos grupos proprietários dos complexos 
agroexportadores; e, fundamentalmente, 2) a construção de uma agência especificamente vinculada aos quadros da agremiação, com prerrogativas formuladoras e decisórias. A instituição continuaria, ao longo da sua história, a manter essa estratégia, na repetição de organização contínua de congressos e exposições.

Dessa forma, naquele congresso, Fernandes Pinheiro, representando os dirigentes do Clube de Engenharia, exerceria com desenvoltura as funções orgânicas que caracterizavam os agentes daquele aparelho privado de hegemonia, inclusive consciente de que a construção de demandas a serem veiculadas com eficácia dependia, segundo suas próprias palavras, "da intervenção do Governo e maior número ainda da intervenção da opinião pública"24, posto "que reunir a congregação, fazendo convergir para um fim comum todos os esforços, adquire uma força assombrosa e produz os mais brilhantes resultados". ${ }^{25}$

Temários discutidos no $1^{\circ} \mathrm{CEFB}^{26}$

\begin{tabular}{|c|c|c|}
\hline Dia da Sessão & Matéria & Sócios pareceristas \\
\hline 14 de julho & $\begin{array}{l}\text { I- sobre o cruzamento de duas estradas } \\
\text { de ferro }\end{array}$ & $\begin{array}{l}\text { Wallace Gama Cochrane; Januário de Oliveira; } \\
\text { Eduardo Klingelhoefer }\end{array}$ \\
\hline 17 de julho & II - telégrafo das estradas de ferro & $\begin{array}{l}\text { Mello Barreto; José Américo dos Santos e } \\
\text { Aarão Reis }\end{array}$ \\
\hline 19 de julho & $\begin{array}{l}\text { III - redução das tarifas das estradas de } \\
\text { ferro }\end{array}$ & F. Mayrinck, Mello Barreto; Herculano Penna \\
\hline 29 de agosto & $\begin{array}{l}\text { IV - sistema de garantia de juros às } \\
\text { empresas de estradas de ferro }\end{array}$ & $\begin{array}{l}\text { Pedro Betim, A. M. Oliveira Bulhões; } \\
\text { Wallace Cochrane }\end{array}$ \\
\hline 19 de julho & $\begin{array}{l}V \text { - zonas privilegiadas das estradas de } \\
\text { ferro }\end{array}$ & $\begin{array}{l}\text { José Américo dos Santos e André Gustavo Paulo } \\
\text { de Frontin }\end{array}$ \\
\hline 29 de julho & VI - plano geral da viação férrea & $\begin{array}{l}\text { A. M. Oliveira Bulhões, Firmo José de Mello, } \\
\text { Jorge Rademarker Grunewald }\end{array}$ \\
\hline 1 de agosto & $\begin{array}{l}\text { VII - determinação do coeficiente da } \\
\text { resistência dos trens }\end{array}$ & $\begin{array}{l}\text { Carlos Conrado de Niemeyer, Raymundo Teixeira } \\
\text { Belfort Roxo e Henrique Hargreaves }\end{array}$ \\
\hline 8 de agosto & $\begin{array}{l}\text { VIII - revisão da lei de desapropriação para } \\
\text { uso das estradas de ferro }\end{array}$ & $\begin{array}{l}\text { Firmo José de Mello, Francisco Pereira Passos } \\
\text { e Paulo de Frontin }\end{array}$ \\
\hline 10 de agosto & IX - vias navegáveis do Brasil & $\begin{array}{l}\text { Jeronymo Moraes Jardim, Francisco Pereira Passos, } \\
\text { R. F. Belfort Roxo }\end{array}$ \\
\hline 10 de agosto & $\begin{array}{l}\text { X - o regulamento de } 26 \text { de abril de } 1857 \\
\text { sobre a polícia e segurança das estradas } \\
\text { de ferro }\end{array}$ & Francisco Pereira Passos e Joaquim M. R. Lisboa \\
\hline 14 de agosto & $\begin{array}{l}\mathrm{XI} \text { - os impostos municipais sobre os } \\
\text { gêneros que se servem das estradas } \\
\text { de ferro em demanda dos mercados } \\
\text { consumidores ou exportadores }\end{array}$ & $\begin{array}{l}\text { Domingos José Rodrigues, F. P. Mayrinck } \\
\text { e Luiz Bittencourt Sobrinho }\end{array}$ \\
\hline 22 de agosto & $\begin{array}{l}\text { XII - as bases gerais para a discriminação } \\
\text { da receita e despesa; movimento de } \\
\text { passageiros e mercadorias e mais dados } \\
\text { estatísticos do tráfego das estradas de ferro }\end{array}$ & $\begin{array}{l}\text { Jorge Rademarker Grunewald, João Carvalho } \\
\text { Borges Junior e Álvaro Rodovalho Marcondes } \\
\text { dos Reis }\end{array}$ \\
\hline
\end{tabular}

Fonte: REIS, Aarão Leal de Carvalho (Org.) Primeiro Congresso das Estradas de Ferro do Brasil. Archivos dos Trabalhos. Rio de Janeiro: Clube de Engenharia, 1882.

As formulações políticas no Segundo Reinado, por parte dos dirigentes imperiais, transitara essencialmente por entre a garantia de uma condução hegemônica quanto às estruturas do que significava a relação entre o poder local e o seu peso na correlação de forças daquele período. 0 projeto centralizador, realizado pelos intelectuais orgânicos da fração hegemônica cafeeira fluminense e demais grupos sob a sua direção, visou fundamentalmente a garantir a prevalência dessa hegemonia frente aos demais grupos locais regionais - alguns dirigidos, outros dominados. Entretanto, no embate dentro do que significava a arena de lutas na sociedade política, tal projeto centralizador via-se, a cada dia, com menor capacidade de construir coesão dentro do bloco no poder. 0 enfraquecimento dessa perspectiva frente a uma construção de certa noção "federalista" começava a se tornar efetiva. 


\section{Início de um projeto para uma agência na sociedade política}

Ecoando a fala de Pinheiro no Congresso de 1882, que dizia que muitas questões defendidas naquela reunião "estariam hoje resolvidas se houvesse junto ao Ministério das Obras Públicas um 'Conselho Superior Consultivo'"27, iniciava-se a primeira campanha efetiva e defendida pelo Grupo Dirigente do Clube de Engenharia.

A campanha organizada por aqueles agentes no $1^{\circ}$ Congresso das Estradas de Ferro, sintetizada nos discursos de abertura e encerramento da presidência do evento defendendo um Conselho Superior Consultivo no Ministério da Agricultura Comércio e Obras Públicas (MACOP), começava a esboçar sua materialização na sociedade política logo no início do ano seguinte ao evento. Em 11 de janeiro de 1883, publicava-se uma Portaria do MACOP "providenciando a organização de um regulamento para fiscalização dos estudos, construção e tráfego das estradas de ferro" ${ }^{2}{ }^{8}$

Segundo a mesma Portaria, comporiam a comissão para elaboração do projeto de regulamento, os engenheiros Antonio Augusto Fernandes Pinheiro, Raimundo Teixeira Belfort Roxo e José Freire Parreiras Horta. ${ }^{29}$ Além de integrarem o Grupo Dirigente do Clube de Engenharia, esses quadros também tinham participado do Instituto Politécnico Brasileiro e compuseram o grupo de sócios que, a partir daquela agremiação, fundaram o Clube. Também os unia o fato de terem exercido diversos cargos no Ministério da Agricultura, Comércio e Obras Públicas. ${ }^{30}$

Assim, esses agentes deveriam especificamente "organizar um projeto de divisão do Império em distritos fiscais e formular regulamento para a fiscalização de estudos, construção e tráfego das estradas de ferro". Além disso, do regulamento deveria constar uma "fiscalização exata, metódica e rigorosa, que [...] determine a regular aplicação dos dinheiros nacionais e habilite o governo a resolver com pleno conhecimento da matéria" sobre as companhias de estrada de ferro com garantias de juros, administradas por particulares. Tal projeto de regulamento deveria, além de tudo, compilar "as disposições que servem atualmente de norma ao modo de proceder dos agentes do governo nesse ramo de serviço" ${ }^{31}$

Portanto, essa comissão estava em sintonia, num primeiro momento, com as propostas feitas na realização do $1^{\circ}$ Congresso das Estradas de Ferro, que demandavam a concretização de uma instância no MACOP, reguladora e fiscalizadora sobre as estradas de ferro e demais obras públicas relacionadas, com o caráter independente de outras Diretorias das Obras Públicas. Consolidava-se, aos poucos, o pleito do Grupo Dirigente do Clube de Engenharia de construção de uma agência vinculada diretamente e somente ao ministro.

Embora a Inspetoria Geral das Estradas de Ferro do Brasil tenha sido regulamentada e aprovada pelo Decreto n 8947 de 19 de maio de 1883, apenas em 1892 uma Inspetoria Geral seria, efetivamente, instalada. É possível inferir que os conflitos gerados por tal regulamentação, no que diz respeito à complexidade das frações hegemônicas ou não hegemônicas - distintas por diferentes posições, diferentes interesses, inclusive interesses regionais cada vez mais acentuados -, fatalmente bloquearam a materialização de uma única agência centralizadora tal qual formulada. A inexistência de registros, mesmo oficiais, sobre esta não-efetivação reforça, em nosso juízo, a dimensão desses embates na sociedade política. Aliás, foi no mesmo ano da concretização da Inspetoria Geral, que uma lei de 1892 do governo de São Paulo estabelecia "ser livre a qualquer particular ou empresa o direito de construir e explorar estradas de ferro" ${ }^{32}$ Exemplo do que significava a disputa entre grupos de interesses conflitantes e a posição estratégica ocupada pela regulamentação daquela agência no contexto destes embates.

0 efeito da construção de uma agência, formulada durante $01^{\circ}$ Congresso das Estradas de Ferro, tornou-se exemplar para aqueles dirigentes do Clube de Engenharia no sentido de ampliar a sua representatividade, em processo de materialização tanto na sociedade civil quanto na sociedade política, frente às frações agrárias. Decorre, ao mesmo tempo, que a construção de sua versão aparelhada na sociedade política significava para esses agentes uma prerrogativa primordial naquela primeira década de existência do Clube.

Na sequência do Decreto antes mencionado, seria publicado o Decreto no 8959 de 21 de junho de 1883, ${ }^{33}$ que efetivava o reconhecimento de uma parcela do grupo dirigente do Clube de Engenharia para compor a comissão de 
estudo para a viabilização de uma Linha Auxiliar ao traçado da E. F. D. Pedro II, entre o Vale do Paraíba e o Rio de Janeiro. Os nomes que integravam essa comissão referendavam os agentes vitoriosos nas controvérsias do referido Congresso. Eram eles: Francisco Bicalho, Carlos Conrado de Niemeyer e André Gustavo Paulo de Frontin, mantendo, portanto, a sua reafirmação na sociedade política.

Os pareceres consolidados no fim das reuniões do Congresso continuaram, em sua maioria, reinscritos pelo grupo dirigente do Clube de Engenharia na sociedade política. Naquela altura, a agremiação já garantia a predominância de quadros no MACOP, particularmente na Diretoria das Obras Públicas, embora essa agência ainda não tivesse uma Inspetoria formuladora e com um grau de autonomia reivindicada pelo grupo dirigente da agremiação. 0 Congresso mencionado significou, portanto, a visibilidade de algumas propostas definidoras para as políticas de construção e transporte ferroviário, principalmente.

Tratava-se, portanto, do aparelhamento dos interesses das frações agrárias da classe dominante, assim como de um empresariado incipiente ligado às atividades de obras públicas e engenharia, que disputavam permanentemente como variadas frações a prerrogativa de atendimento de seus interesses no âmbito da sociedade política.

\section{Considerações finais}

Com formação escolar e prática profissional voltadas para o encontro das necessidades demandadas pelas frações agrárias hegemônicas, de agentes em sintonia com os últimos avanços tecnocientíficos e aptos a desenvolver e manter 0 complexo agroexportador, no que este poderia prover em termos de modernidade, os engenheiros civis se encontravam coagidos em uma ambiguidade semelhante àquela característica das próprias transformações socioeconômicas, bem como culturais, que contribuíram para a sua formação.

Assim, os projetos, plantas, cartas, planos vinculados diretamente à engenharia civil que apareciam nos temários do $1^{\circ}$ Congresso das Estradas de Ferro do Brasil, ficavam, na verdade, atrelados aos interesses das frações proprietárias agrárias, particularmente aquelas relativas aos setores que se tornavam menos dinâmicos. Tal condição encarregava-se de ajustar as ações daqueles agentes ao restrito espaço reservado e permitido às suas iniciativas. Aliás, dentro de uma concepção de mundo que eles mesmos ainda partilhavam, ainda que de maneira ambígua.

A ação política, representativa das frações hegemônicas agrárias, marcou grande parte das questões políticas disputadas de forma acirrada ao longo da segunda metade do século XIX e trouxe, evidentemente, características específicas à prática profissional dos engenheiros civis. As Escolas de Engenharia, o Instituto Politécnico Brasileiro e, mais tarde, o Clube de Engenharia desempenhariam um papel de destaque nesse processo, dado por meio da ascensão social e profissional conseguida graças à formação tecnocientífica e ao crescente prestígio político dos engenheiros como intelectuais organizadores dos interesses dos grupos sociais dominantes.

Ainda naquele decênio inicial de sua existência, a correlação de forças internas à agremiação estava se definindo e, embora a composição social do grupo dirigente já apontasse para a prevalência de agentes vinculados às empresas e atividades profissionais ligadas à engenharia civil, constituir-se-iam posições internas diferenciadas no aspecto político. Da mesma forma, se os agentes integrantes do Clube de Engenharia, naquele momento, se articulavam no sentido de se distinguirem de seus "antecessores" do IPB, por outro lado, continuavam igualmente subordinados aos limites estruturais impostos pela economia agroexportadora. Em outras palavras, se, por um lado, o Grupo Dirigente da agremiação em questão subordinava-se aos interesses particulares das frações agrárias dominantes, por outro lado, manifestava-se de maneira favorável aos interesses específicos de um empresariado em ascensão.

Naquela década do fim do século, o Grupo Dirigente do Clube de Engenharia, mesmo em meio às suas ambiguidades, consolidava-se como um importante aparelho privado de hegemonia, organizando demandas, inscrevendo agências e quadros na sociedade política. Dentro desse movimento, as ações políticas estavam mais complexas e 
já não passavam única e exclusivamente pelos tradicionais partidos políticos. 0 intricado processo de formação da classe dominante no Brasil, que se elaborava por disputas entre as diferentes frações dominantes lutando, cada qual, pela prevalência de seus interesses particulares sobre o conjunto do país, comportava cada vez mais vários espaços e agências em disputa. Certamente, uma agência que centralizasse todo o sistema viário do país teria forte impacto sobre a correlação de forças políticas vigentes.

Assim, mesmo diante da grave crise que se instalava no bloco histórico imperial-escravista, o Grupo Dirigente do Clube de Engenharia demonstrava a sua capacidade de mobilização, até mesmo de agentes representativos de projetos políticos divergentes, dentro da correlação de forças do fim do Império. Os intelectuais agremiados no Clube já haviam acumulado experiência suficiente para compreender que, naquele momento, a sociedade política mantinhase no limite de "equilíbrios instáveis", como diria Gramsci, e que a garantia daquele aparelho privado de hegemonia estava além do regime que desmoronava.

A capacidade de organizar uma agência e principalmente dirigi-la era o que diferenciava o Clube de Engenharia de outras associações contemporâneas, e foi um dos motivos que garantiu àquele Grupo Dirigente ultrapassar a crise hegemônica do bloco histórico Imperial.

\section{Notas e referências bibliográficas}

Pedro Eduardo Mesquita de Monteiro Marinho é doutor em História pela Universidade Federal Fluminense. Pesquisador adjunto do Museu de Astronomia e Ciências Afins/MCT e professor do Programa de Pós-Graduação em História da UniRio. Este texto é uma versão resumida do $4^{\circ}$ capítulo da tese de doutorado Ampliando o Estado Imperial: os engenheiros e a organização da cultura no Brasil oitocentista, 1874-1888. Niterói: Universidade Federal Fluminense, 2008a, defendida no Programa de Pós-Graduação em História da UFF, sob a orientação da profa dra Sonia Regina de Mendonça. E-mail: pedro@mast.br.

1 MENDONÇA, Sonia Regina de. A balança, a régua e 0 arado: sistemas de ensino e habitus de classe na Primeira República. Cadernos do ICHF. Niterói: UFF, 48, nov. de 1992.

2 MARINHO, Pedro Eduardo Mesquita de Monteiro. Ampliando o Estado Imperial: os engenheiros e a organização da cultura no Brasil oitocentista, 1874-1888. Niterói. Tese (Doutorado em História), Universidade Federal Fluminense, Niterói, 2008a.

3 A questão dos "melhoramentos" pode ser vista em TURAZZI, Maria Inez. As artes do ofício: fotografia e memória da engenharia no século XIX. Tese de Doutorado em Arquitetura e Urbanismo. São Paulo: USP, 1997. De acordo com o Diccionario da língua portugueza, datado de 1889, de autoria de Antonio Morais Silva, a definição para "melhoramentos públicos" referia-se às "obras de utilidade ou embelezamento feitas pelo Estado, pelo município etc. para uso e gozo da população: v. g. abertura de ruas, praças, abastecimento de águas, esgotos, iluminação, viação acelerada, edificações, jardins, etc." Cf. SILVA, Antonio Morais. Diccionario da língua portugueza. Rio de Janeiro: Editora Empreza Litteraria Fluminense de A. A. da Silva Lobo, 1889. Os referidos melhoramentos possuíam uma relação direta com 0 trabalho dos engenheiros e, por sua vez, com as obras públicas no século XIX. Além disso, esses melhoramentos poderiam ser tanto "materiais", "morais" ou "públicos", como também "urbanos". Mas se deve reter que o termo "melhoramentos", na designação de época, referia-se a um largo campo de significados, desde "obras públicas" até uma noção próxima de "civilizar". Cf. MARINHO, op. cit.

4 Revista do Instituto Politécnico Brasileiro. Rio de Janeiro: Tip. Nacional. Tomo XII, 1878, 2a parte, p. 3. Prêmio anual direcionado ao melhor trabalho de engenharia entre os sócios do Instituto Politécnico Brasileiro. Cf. Engenharia Imperial: 0 Instituto Politécnico Brasileiro (1862-1880). Niterói: Dissertação de Mestrado em História, Universidade Federal Fluminense, Niterói, 2002

5 Dentre outros: BRITO, José do Nascimento. Meio século de estrada de ferro.
Rio de Janeiro: Livraria São José, 1961; GRAHAM, Richard. Grã-Bretanha e o início da modernização no Brasil (1850-1914). São Paulo: Brasiliense, 1973; SAES, Flavio A. Marques de. As ferrovias de São Paulo, 1870-1940. São Paulo: Hucitec, 1981; _. . A grande empresa de serviços públicos na economia cafeeira, 1850-1930. São Paulo: Hucitec, 1986; DAVID, Eduardo Gonçalves. 127 anos de ferrovia. Rio de Janeiro: AENFER, 1985; . Estrada de Ferro Central do Brasil - A ferrovia e sua história. Rio de Janeiro: AENFER/ AMUTREM, 1998; TELLES, Pedro Carlos da Silva. História da Engenharia no Brasil - séculos XVI a XIX. v. 1, 2a ed. Rio de Janeiro: Clavero, 1994; VARGAS, Milton (Org.). História da técnica e da tecnologia no Brasil. São Paulo: UNESP, 1994; KANTINSKY, Júlio Roberto. "Ferrovias Nacionais". In: MOTOYAMA, Shozo (org.) Tecnologia e industrialização no Brasil: uma perspectiva histórica. São Paulo: UNESP/CEETEPS, 1994; LAMOUNIER, Maria Lúcia. Ferrovias, agricultura de exportação e mão-deobra no Brasil no século XIX. História econômica \& História de empresas, São Paulo: Hucitec/ABPHE, vol.3 (1), 2000, p. 43-76; HARDMAN, Francisco Foot. Trem Fantasma: a modernidade na selva. $2^{\mathrm{a}}$ ed. São Paulo: Companhia das Letras, 2005

6 BLASENHEIM, Peter L. As ferrovias de Minas Gerais no século XIX. Locus: revista de história. Juiz de Fora: NHR / EDUFJF, vol. 2 (2), 1996, p. 81-110.

7 RABELLO, Andrea Fernandes Considera Campagnac. Os caminhos de ferro da província do Rio de Janeiro. Ferrovias e café na $2^{\mathrm{a}}$ metade do século XIX. Niterói, 1996. Dissertação (Mestrado em História) - Instituto de Ciências Humanas e Filosofia, Universidade Federal Fluminense, Niterói, 1996.

8 MARINHO, Pedro Eduardo Mesquita de Monteiro. De politécnicos a engenheiros: a engenharia entre a sociedade civil e a sociedade política no Brasil oitocentista. In: ALMEIDA, Marta de; VERGARA, Moema de Rezende (Orgs.). Ciência, história e historiografia. 1 ed. São Paulo: Via Lettera, 2008b, v. 1, p. 13-24.

9 GRAMSCI, Antonio. Maquiavel, a política e o Estado Moderno. Rio de Janeiro: Civilização Brasileira, 1968, p. 33. 
10 Gramsci formula aqui uma noção de sociedade civil, na qual as corporações e instituições sociais e políticas, "aparelhos privados de hegemonia", definem o "conteúdo ético do Estado", ou seja, a substância moral atinge a sua forma mais elaborada. Ou, como afirma o próprio Gramsci, "é preciso distinguir a sociedade civil tal como é entendida por Hegel e no sentido em que é muitas vezes usada nestas notas - isto é, no sentido de hegemonia política e cultural de um grupo social sobre toda a sociedade, como conteúdo ético do Estado - do sentido em que Ihe dão os católicos, para os quais a sociedade civil, ao contrário, é a sociedade política ou o Estado, em oposição à sociedade familiar e à Igreja". Ibid., p. 225, sem grifo no original.

11 MARINHO, op. cit., 2008b.

12 Sonia Mendonça, embora faça referência à Sociedade Nacional de Agricultura, alvo de seu estudo, aponta uma série de observações extremamente relevantes e que acreditamos fundamentais em relação a aparelhos como o Clube de Engenharia, pois "a prática da organização de congressos e exposições que trouxessem a público seus pontos de vista e posição consistiu numa estratégia das mais usadas [...], de modo a afirmarse como grupo de pressão e formadora de opiniões no bojo da classe proprietária. Uma vez que se sucedessem conjunturas menos favoráveis a certo(s) produto(s) ou complexo(s), a [agremiação] patrocinava um encontro de ampla abrangência setorial/geográfica, de modo a produzir 0 consenso quanto aos interesses envolvidos, transformando-0 em instrumento de pressão no aparelho de Estado. Em várias ocasiões, tal intenção explicitava-se já ao longo da preparação dos eventos, quando do estabelecimento de seus temários e elenco de mesas debatedoras, numa tentativa de disciplinar o que e como discutir, de modo a configurar 0 uno com base no diverso". MENDONÇA, Sonia Regina de. 0 ruralismo brasileiro. São Paulo: Hucitec, 1997, p. 50-51.

13 MARINHO, op. cit., 2008a.

14 GRAMSCl, Antonio. Cadernos do cárcere. Vol. 5. Rio de Janeiro: Civilização Brasileira, 2002, p. 99.

15 MARINHO, op. cit.

16 MARINHO, op. cit.

17 Embora, na historiografia relativa às estradas de ferro no Brasil, existam referências a este importante Congresso, até o presente momento não há estudos que tenham aprofundado as suas questões. Podemos citar o clássico trabalho de Ademar Benévolo (BENÉVOLO, Ademar Benévolo. Introdução à história ferroviária do Brasil. Estudo social, político e histórico. Recife: Edições Folha da Manhã, 1953), além do livro de Pedro Carlos da Silva Telles (TELLES, op. cit.). Cabe esclarecer que as fontes primárias deste Congresso estão restritas às atas do mesmo, organizadas por Aarão Reis (REIS, Aarão Leal de Carvalho (Org.). Primeiro Congresso das Estradas de Ferro do Brasil. Archivos dos Trabalhos. Rio de Janeiro: Club de Engenharia, 1882).

18 REIS, op. cit.

19 Antonio Augusto Fernandes Pinheiro (presidente); Francisco Pereira Passos ( $1^{\circ}$ vice-presidente); Chales Paul Mackie ( $2^{\circ}$ vice-presidente); Eduardo Klingelhoefer (secretário); Conrado Jacob Niemeyer (tesoureiro); além de Francisco de Paula Mayrink, Carlos Conrado de Niemeyer, Antonio Paulo de Mello Barreto, Antonio Maria de Oliveira Bulhões, João Teixeira Soares, Carlos Alberto Morsing, Jeronymo Rodrigues de Moraes Jardim, José Américo dos Santos, Raymundo Teixeira Belfort Roxo e Carlos Hargreaves. Cf. MARINHO, op. cit.

20 Antonio Fernandes Pinheiro estudou na Europa em companhias de estrada de ferro francesas e acompanhou de perto as de Bruxelas e Inglaterra. Acumulou postos na sociedade política, na direção da E. F. D. Pedro II, em que chefiou a construção de vários ramais. Foi durante a sua presidência, nos mandatos de 1881 a 1884, que a inserção dos profissionais ligados às atividades de engenharia na Estrada de Ferro D. Pedro II obteve visibilidade. Em primeiro lugar, por estar aquela companhia sob direção e condução, em sua totalidade, de profissionais nacionais, já desde 0 início da década de 1870 e, em segundo, pela projeção que tais profissionais conquistariam mediante seus aparelhos privados de hegemonia, especificamente o IPB e o Clube de Engenharia. Além de presidente do Clube de Engenharia, era também um quadro de destaque da Sociedade Auxiliadora da Indústria Nacional (SAIN), dirigindo a Seção da Indústria Fabril de 1880 a 1885. No intervalo dessas décadas, e referendando sua posição orgânica na sociedade política, no fim de 1883, Pinheiro seria nomeado pelo governo para chefiar uma comissão do Ministério da Agricultura, Comércio e Obras Públicas (MACOP) encarregada da aquisição na Europa e nos EUA de material para as estradas de ferro e outras obras públicas. Além disso, teria a incumbência de negociar a liquidação de juros devidos às ferrovias e portos com sede na Europa. Pinheiro havia sido sócio do Instituto Politécnico Brasileiro até meados de 1880, quando se juntaria aos demais engenheiros e empresários que, aglutinados em torno de Conrado Jacob de Niemeyer, fundariam o Clube de Engenharia. Sua trajetória não foge, em essência, a da maioria dos engenheiros de sua geração. Cf. MARINHO, op. cit.

21 VAlLADÃO, Manuel. Apontamentos históricos do Clube de Engenharia. Manuscrito, 1903.

22 REIS, op. cit., p. 21-23, 33-34.

23 PINHEIRO, Antonio et. al. I centenário das ferrovias brasileiras. Rio de Janeiro: IBGE, 1954, p. 250.

24 REIS, op. cit., p. 22.

25 bid., p. 32.

26 Os dois temários tratados no congresso e que suscitaram maiores controvérsias foram os relativos à "redução das tarifas das estradas de ferro" e ao "sistema de garantia de juros às empresas de estradas de ferro". Não obstante, é importante destacar que o congresso esteve mais concentrado em questões administrativas, políticas e econômicas do que em discussões especificamente de natureza técnica. Cf. MARINHO, op. cit.

27 Ibid., p. 22, 33.

28 CORUJA JUNIOR, Antonio Alvares Pereira (Org.). Repertório das leis, decretos, consultas, instruções, portarias, avisos e circulares relativos à concessão, administração e fiscalização das estradas de ferro. Rio de Janeiro: Imprensa Nacional, 1886, p. 434.

29 MARINHO, op. cit.

30 lbid.

31 CORUJA JUNIOR, op. cit., p. 434.

32 Cf. TELLES, op. cit., p. 386.

33 BRASIL. Coleção de leis do Brasil. Decreto nº 8959 de 21 de junho de 1883.

[ Artigo recebido em 08/2010 | Aceito em 10/2010 ] 